\title{
Editorial: Ignorance and Markets
}

It may not be true that no one predicted the recent crash in the financial world. But it is certainly true that most well-informed observers and participants, including most importantly those who believed they were actually running things, were caught unawares. If they had been aware, they would have been able to avoid the worst consequences, at least for themselves, and even profit from the situation.

The 2008 financial crash has been compared to the fall of the Berlin Wall, in that just as the one signalled the end of an uncritical belief in socialism, at least of a centralised sort, the other signals the end to an uncritical belief in markets.

Let us leave aside the point that the markets of 2008 were actually heavily regulated in all sorts of ways, and so hardly unfettered. There is in fact an interesting parallel between 1989 and 2008 in one significant respect. Both events were largely unforeseen.

In one sense this is encouraging. For all our knowledge and technology there is much, even in human affairs, which is unpredictable and uncontrollable. This is, in a sense, judgment on hubris. It can also be liberating, particularly for those who do not see themselves as masters of the universe.

But should 2008 be seen as a decisive moment as far as belief in markets is concerned? Much will depend on what is meant by a market, no easy question when, as already mentioned, no markets to-day are unfettered, and are not likely to be in the foreseeable future.

We should, though, not forget that for followers of Adam Smith, such as Hayek, one of the main philosophical arguments in favour of markets was precisely the unpredictability of human action and of events more generally. From this perspective markets are not seen as perfect predictors, which there cannot be. But in situations of uncertainly they are seen as the most efficient and least hazardous way of disseminating information in a society and of responding to what cannot be predicted. It would be somewhat paradoxical if a failure of prediction was in itself taken to be an argument against a system which takes unpredictability as its starting point. 